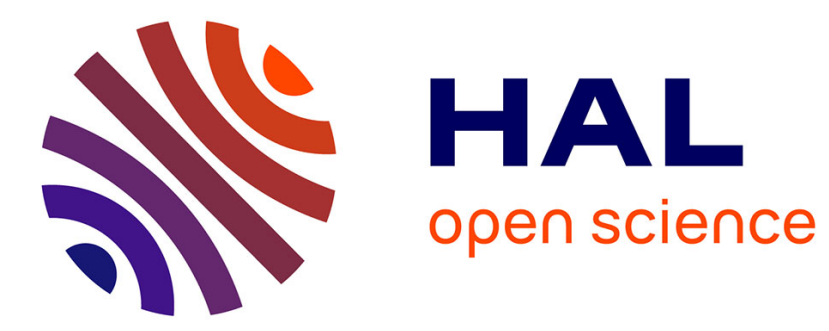

\title{
Local Structure and Size Effects in Nanophase Palladium
}

S. de Panfilis, F. d'Acapito, V. Haas, H. Konrad, J. Weissmüller, F. Boscherini

\section{To cite this version:}

S. de Panfilis, F. d'Acapito, V. Haas, H. Konrad, J. Weissmüller, et al.. Local Structure and Size Effects in Nanophase Palladium. Journal de Physique IV Proceedings, 1997, 7 (C2), pp.C2-979-C2981. 10.1051/jp4:19972107 . jpa-00255164

\section{HAL Id: jpa-00255164 https://hal.science/jpa-00255164}

Submitted on 1 Jan 1997

HAL is a multi-disciplinary open access archive for the deposit and dissemination of scientific research documents, whether they are published or not. The documents may come from teaching and research institutions in France or abroad, or from public or private research centers.
L'archive ouverte pluridisciplinaire HAL, est destinée au dépôt et à la diffusion de documents scientifiques de niveau recherche, publiés ou non, émanant des établissements d'enseignement et de recherche français ou étrangers, des laboratoires publics ou privés. 


\title{
Local Structure and Size Effects in Nanophase Palladium
}

\author{
S. De Panfilis, F. d'Acapito*,1 , V. Haas**, H. Konrad**, J. Weissmüller** and F. Boscherini \\ INFN, Laboratori Nazionali di Frascati, P.O. Box 13, 00044 Frascati, Rome, Italy \\ * CNR, piazzale A. Moro, 00185 Roma, Italy \\ ** Universität des Saarlandes, 66121 Saarbrücken, Germany
}

\begin{abstract}
The connection between local structure and the grain size distribution in nanophase palladium is studied by XAFS and $x$-ray diffraction (XRD). We show that there is a reduced average coordination number in all samples; this reduction is compatible with a size effect, contradicting previous XAFS measurements. Both a first shell analysis and a full analysis up to the 8 th coordination shell, including multiple-scattering, are reported.
\end{abstract}

\section{INTRODUCTION}

The interest in the local structure of nanophase materials [1] stems from the high density of grain boundaries (GB) present; in fact, one can attempt to study the structure of these defects by volume sensitive methods. Fundamental questions are: what is the local structure of a GB? is it different in a coarse grained or nanophase material? The proposal [2] of a GB radial distribution function lacking either short-range or long-range order has been controversial with results from different techniques either supporting or rejecting this model.

XAFS has played an important role in this discussion[3]. In fact, all measurements reported to date[4-9] have shown a reduction of average coordination numbers $\left(\mathrm{CN}^{\prime} \mathrm{s}\right)$ in the first few coordination shells. In a set of GB's with a random distribution of crystallographic orientations reduced CN's have two possible origins. In the limit of incoherent, nonreconstructed GB, where the perfect crystal extends all the way to the boundary plane the reduction is identical to that of a free surface; the important parameter is the surface-to-bulk (SBR) ratio of the ensemble. A second origin could be the presence of GB's with low packing density and with a wide distribution of interatomic spacings. We note that the reduction in CN's previously reported by XAFS was greater than that compatible with the first origin of reduction of CN's.

In the present paper we report XAFS measurements of n-Pd samples which have been carefully characterized by XRD [10]. We report a full analysis up to the 8th coordination shell which complements first shell results already published[11]. Related results on $\mathrm{n}-\mathrm{Cu}$ have been published, at the same time as ours, by other authors [12].

\section{SAMPLE PREPARATION AND EXPERIMENTAI}

Six samples of $\mathrm{n}-\mathrm{Pd}$ were prepared by inert gas condensation with different treatments following the deposition. One sample (n.1) was not consolidated. All other samples were consolidated in situ under high vacuum for 5 to 10 minutes at $1-2$ $\mathrm{GPa}$; at this stage samples have a density from 84 to $87 \%$ of coarse grained Pd. Following room temperature consolidation one sample was kept at liquid Nitrogen temperature (LNT) up to 1 week before measurement in order to reduce room temperature (RT) grain growth. Two samples were stored at RT for different periods of time and the remaining two samples were subjected to annealing and hot-pressing procedures. The particle size distribution functions, $n$ (D), for all our samples has been determined by indirect deconvolution of Bragg peaks[10]. The average grain size can be determined from this and it is listed in table 1 , together with sample history.

In order to perform XAFS experiments a thin $(\approx 10 \mu \mathrm{m})$, homogeneous sample is required[13]; consequently much care was devoted to this aspect. Notice that all known experimental artifacts tend to reduce the measured coordination numbers, not to enhance them. The samples were lightly ball milled at LNT in order to produce a powder which was then dispersed in toluene using an ultra-sound bath. Only the finest particles were then deposited on a cellulose membrane forming a homogeneous sample. XAFS measurements were performed on the GILDA CRG (D8) beamline of the ESRF. A Si(311)

Table 1: Sample characteristics, $\langle\mathrm{D}\rangle_{\mathrm{A}}$ is the area-weighted average particle size.

\begin{tabular}{|c|c|c|}
\hline Sample & Preparation /Treatment & $\langle\mathrm{D}\rangle_{\mathrm{A}}(\mathrm{nm})$ \\
\hline 1 & Not compacted & 8.4 \\
\hline 2 & Stored at LNT & 11.5 \\
\hline 3 & Stored at RT for 1 month & 16.7 \\
\hline 4 & Stored at RT for 2 weeks & 12.2 \\
\hline 5 & Hot pressed for 2 days $3.2 \mathrm{GPa}, 100^{\circ} \mathrm{C}$ & 11.5 \\
\hline 6 & As n.S, then annealed for 1 hour at $160^{\circ} \mathrm{C}$ & 13.0 \\
\hline
\end{tabular}

\footnotetext{
${ }^{1}$ Mailing address: GILDA CRG, ESRF, BP. 220, 38043 Grenoble, France.
} 


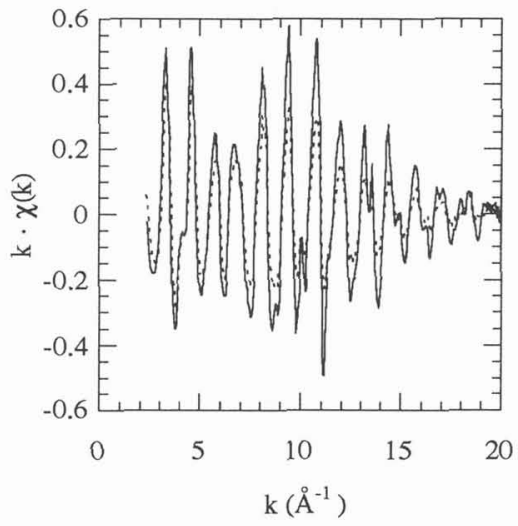

Fig. 1a: Raw XAFS data; symbols explained in Fig. 1 b.

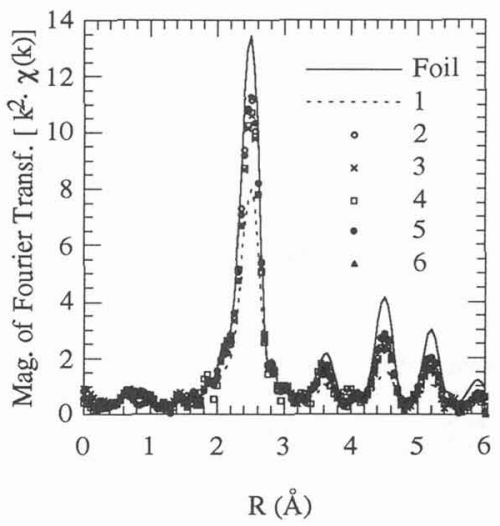

Fig. 1b: Fourier transform of spectra of Fig. la.

independent crystal monochromator with dynamical sagittal focussing was used[14]. Harmonics rejection was obtained by detuning the crystal to $1 / 3$ of the rocking curve maximum using a closed loop feedback controller, the absence of harmonics was checked with a Ge detector. XAFS spectra were measured in the transmission mode with Ar filled ionization chambers in the energy range $24-26 \mathrm{keV}$; all spectra were measured at $77 \mathrm{~K}$. A coarse grained Pd foil was measured as a reference.

\section{RESULTS}

Representative XAFS functions are reported in Fig.1a. The Fourier Transforms (FT) for all samples are displayed in Fig. 1b. It is apparent that the spectra show different amplitudes and can be grouped in three sets in order of decreasing amplitude: the coarse grained foil, samples 2 to 6 (i.e. all the compacted samples) and sample 1 (the un-compacted sample).

Analysis was performed in two steps. First shell structural parameters were obtained by traditional (FT) techniques. The R-space signal (obtained by FT in the range $3-20 \AA^{-1}$ ) was back-FT in the range 1.8-3.2 $\AA$. Structural parameters were obtained by a least squares minimization routine and results are displayed in Tab. 2 . All samples show a reduced coordination number $(\mathrm{CN})$ and a slightly increased mean square relative displacement $\left(\sigma^{2}\right)$ with respect to the foil.

In a second step the GNXAS [15] program was used in order to analyze the spectra up to the $8^{\text {th }}$ coordination shell. First of all, the spectrum of the coarse grained foil was analysed in order to check the theoretical phase shifts and in order to determine $S_{0}{ }^{2}$. The fit was performed in $k$ - space in the range $k=3-20 \AA-1, R=0-8 \AA$, with a total of 12 free parameters. Included in the fit were all two-body signals up to the $7^{\text {th }}$ coordination shell and the following three-body signals: the $90^{\circ}$ and $120^{\circ}$ triangles involving nearest neighbours and the two collinear configurations involving $1^{\text {st }}$ and $4^{\text {th }}$ neighbours on the one hand and $2^{\text {nd }}$ and $8^{\text {th }}$ neighbours on the other. The Fourier transform of the (excellent) fit is displayed in Fig. $2 a$.

Table 2: First shell $\mathrm{CN}$ and $\Delta \sigma^{2}$ and estimates of the $\mathrm{CN}$ assuming a size effect.

\begin{tabular}{|c|c|c|c|c|}
\hline Sample & $\left.\Delta \sigma^{2}\left(10^{-3} \AA^{2}\right) \pm 0.3\right)$ & $\left.\mathrm{CN}_{\operatorname{EXP}} \pm 0.5\right)$ & $\mathrm{CN}_{\alpha}$ & $\mathrm{CN}_{\mathbf{n}(\mathrm{D})}$ \\
\hline Foil & 0 & 12 & - & - \\
\hline 1 & 1.2 & 9.7 & 11.41 & 11.33 \\
\hline 2 & 0.8 & 11.7 & 11.57 & 11.50 \\
\hline 3 & 0.9 & 11.5 & 11.70 & 11.60 \\
\hline 4 & 1.0 & 12.0 & 11.59 & 11.52 \\
\hline 5 & 0.7 & 11.8 & 11.57 & 11.50 \\
\hline 6 & 0.8 & 12.0 & 11.62 & 11.57 \\
\hline
\end{tabular}

While the determination of the 1 st shell $\mathrm{CN}$ is affected by a reasonable error we found that fitting of the higher shells yields unreasonably large ones; consequently, an alternative procedure was used. As described below, the reduction in $\mathrm{CN}$ for nanophase materials can be described by a linear decrease with interatomic distance. The value of the $\alpha$ parameter (eq. 1) was determined from the first shell and was then used in a multi-shell fit (as for the foil); very good fits were obtained, Fig. $2 \mathrm{~b}$.

\section{DISCUSSION}

The first conclusion which can be drawn from the analysis is that for samples 2 to 6 there is no evidence for large reductions in CN's. The $\mathrm{CN}$ found for these samples is, however, different from that of the foil (both from the present analysis and from Fourier - filtering analysis [11]). Thus, in order to interpret the data we have calculated the average coordination number expected for the samples considering only the SBR. For an ensemble of particles compacted into a nanophase 
material with incoherent grain boundaries it can be demonstrated that the reduction in CN scales linearly with interatomic distance R[10]:

$$
\frac{\mathrm{CN}_{\alpha}}{\mathrm{CN}_{\text {ideal }}}=\left(1-\frac{1}{2} \alpha \mathrm{R}\right)
$$

where $\alpha=3 /<D>_{A}$. The first shell CN's estimated using the values of $\angle D>_{A}$ determined by XRD are reported in Tab. 2 . Also reported is a second estimate of $\mathrm{CN}$, obtained by considering the full particle size distribution, $n$ (D) [11].

First shell $\mathrm{CN}$ values for samples 2 to 6 are all quite close to both estimates. Moreover, the multi-shell fits with the experimentally determined $\alpha$ values show very good agreement with the data. The present measurements indicate, therefore, that the reduction of $\mathrm{CN}$ for compacted materials can be explained by a size effect with no evidence of further reduction, provided the particle size distribution is determined. GB's are thus found to be non-reconstructed and incoherent. No evidence is found for disordered GB components. This is the main conclusion of this paper.

The slight enhancement of first shell $\sigma^{2}$ with respect to the coarse grained foil indicates that the process of evaporation and compaction produces a slight distortion of the local environment which is insensitive to further hot pressing or annealing. It is interesting to compare the present result with the determination of disorder by XRD. In fact, an (isotropic) increase of $3 \times$ $10^{-3} \AA^{2}$ in the mean square displacement (MSD) was found by XRD [16], to be compared with the $0.7-1.0 \times 10^{-3} \AA^{2}$ we find for the increase in $\sigma^{2}$. By comparing the numerical results of the two techniques we conclude that the increase in MSD is due in the most part to atomic displacements which are correlated in first coordination shell.

Sample 1 (with a negligible grain boundary density) shows a greatly reduced CNEXP. This fact alone suggests that the origin of the reduction of average coordination number for the compacted samples must be found in a size effect and cannot be attributed to the presence of GB's[8]. The reduction of CNEXP is not, however, reproduced by our estimate. There may be a number of reasons for this, including that our model of size distribution is not correct for uncompacted samples. It may well be that there are many more small diameter grains than presently estimated and that they coalesce during compaction; in fact it has been noted that the determination of the size distribution by XRD may neglect small diameter grains[10].

A XAFS study of $\mathrm{n}$-Cu[12] found that the $\mathrm{CN}$ in the first shell was, within the errors, equal to that of the foil. The main difference with the present study is that surface sensitive TEY detection was used; the near-surface, grain size distribution was not, however, determined and this may be different from that of the bulk. Common to the present work is the conclusion that disordered GB's are not present.

Standard foil

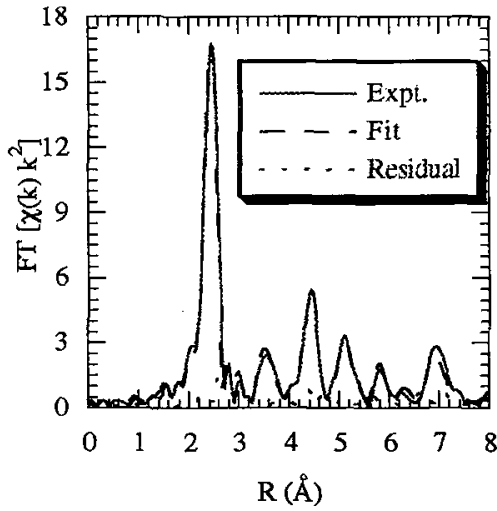

Fig. 2a: Multi-shell fit of standard foil.
Sample 5

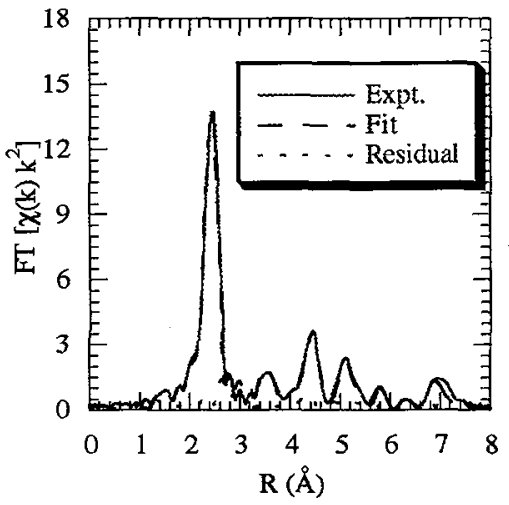

Fig. 2b: Multi-shell fit of sample 5 .

\section{References}

1. H. Gleiter, Progress Mat. Sci. 33 (1989) 223; R.W. Siegel, Mat. Res. Soc. Bull. XV, 10 (1990) 60.

2. X. Zhu, R. Biringer, U. Herr, and H. Gleiter, Phys. Rev. B 35 (1987) 9085.

3. F. Boscherini, in Fundamental Properties of Nanostructured Materials, eds. D. Fiorani \& G. Sberveglieri (World Scientific, Singapore, 1994) p. 88-98.

4. T. Haubold, R. Birringer, B. Lengeler, and H. Gleiter, Phys. Lett. A 135 (1989) 461.

5. T. Haubold, W. Krauss, and H. Gleiter, Phil. Mag. Lett. 63 (1991) 245.

6. T. Haubold, F. Boscherini, S. Pascarelli, S. Mobilio, and H. Gleiter, Phil. Mag. A 66 (1992) 591.

7. T. Haubold, Acta Metall. Mater. 41 (1993) 1769.

8. J.A. Eastman, M.R. Fïtzsimmons, M. Müller-Stach, G. Wallner, and W.T. Elam, Nanostruct. Mater. 1 (1992) 47.

9. A. Di Cicco, M. Benrettoni, S. Stizza, E. Bonetti, and G. Cocco, Phys. Rev. B 50 (1994)

10. J. Löffler and J. Weissmüller, Phys. Rev. B 52 (1995) 7076.

11. S. de Panfilis, F. d'Acapito, V. Haas, H. Konrad, J. Weissmüller, and F. Boscherini, Phys. Lett. A 207 (1995) 397.

12. E. Stern, R.W. Siegel, M. Newville, P.G. Sanders, and D. Haskel, Phys. Rev. Lett. 75 (1995) 3874.

13. E. Stern and K. Kim, Phys. Rev. B 23 (1981) 1981; J. Goulon, C. Goulon Ginet, R. Cortes, and M. Dubois, J. Phys. 43 (1982) 539.

14. S. Pascarelli, F. Boscherini, F. d'Acapito, J. Hrdy, C. Meneghini, and S. Mobilio, Jour. Synch. Rad. 3147 (1996).

15. A. Filipponi, A. Di Cicco, and C.R. Natoli, Phys. Rev. B 52 (1995) 1522; ibidem, p 15135.

16. J.A. Eastman, M.R. Fitzsimmons, and L.J. Thompson, Phil. Mag. B 66 (1992) 667. 